\title{
Educação Integral, territórios educativos e cidadania: aprendendo com as experiências de ampliação da jornada escolar em Belo Horizonte e Santarém
}

\section{Integral Education, education territories and citizenship: learning from the experiences of expansion of the day in school in Belo Horizonte and Santarém}

\author{
Lúcia Helena Alvarez Leite ${ }^{1}$
}

\begin{abstract}
RESUMO
O artigo apresenta o resultado de uma pesquisa sobre a ampliação da jornada escolar desenvolvida em alguns municípios brasileiros, tendo como eixo a Educação Integral/Integrada em suas relações com os territórios educativos. Para isso, será apresentada a experiência de duas cidades brasileiras: Belo Horizonte e Santarém. Apesar de realidades distintas, essas experiências têm algo em comum: os projetos vão para além dos muros da escola, ocupando praças, parques e até rios, entendidos como espaços sociais, construindo, assim, um sentimento de pertencimento à cidade. A experiência de ampliação da jornada escolar nessas cidades revela uma determinada perspectiva de educação que procura transformar a cidade em território educativo, entendendo que a instituição escolar faz parte de uma rede social para garantir a crianças, jovens e adolescentes o direito a uma Educação Integral.
\end{abstract}

Palavras-chave: Educação Integral; territórios educativos; cidadania.

1 Doutora em Educação pela Universidad de Valencia (Espanha), Professora Adjunta da Universidade Federal de Minas Gerais (UFMG), Brasil. 


\begin{abstract}
This article shows the results of a research regarding the expansion of the school hours, developed in some Brazilian municipalities with integral/ integrated education in their relations with the educative territories. For this, the experience in two Brazilian cities: Belo Horizonte and Santarém will be presented. Despite the distinct contexts, these experiences have something in common: the projects go beyond the school walls, reaching squares, parks and even rivers, considered as social areas, thus building a feeling of belonging to the city. The experience of expanding the school hours in those cities reveals a specific perspective of education that intends to transform the city into an educative territory, understanding that schools are part of a social network to ensure to children, youths and adolescents, the right to the integral education.
\end{abstract}

Keywords: integral education; educative territories; citizenship.

\title{
Introdução
}

Este texto tem como objetivo analisar alguns resultados da pesquisa "Educação Integral/Educação Integrada e(m) tempo integral: concepções e práticas na educação brasileira", desenvolvida, entre os anos de 2008 e 2010, por um grupo de universidades públicas federais a partir de solicitação da Secretaria de Educação Continuada, Alfabetização e Diversidade, do Ministério da Educação (SECAD/MEC), por meio de sua Diretoria de Educação Integral, Direitos Humanos e Cidadania (DEIDHUC). A pesquisa procurou mapear experiências de ampliação de jornada no ensino fundamental das redes municipais brasileiras, sendo desenvolvida em duas fases: na primeira etapa foi feita uma pesquisa quantitativa, de amplitude nacional e na segunda, uma pesquisa qualitativa, com estudos de caso de municípios selecionados na primeira etapa da pesquisa.

A análise dos resultados da parte quantitativa da pesquisa trouxe elementos importantes para compreender o processo de ampliação da jornada escolar nos municípios brasileiros. Um dado importante revelado pela pesquisa refere-se à diversidade das experiências, que aparece em quase todos os aspectos analisados: na denominação das experiências, no tipo de atividades, nos espaços utilizados, na organização do tempo, na escolha dos alunos, e também na diferença de realidades entre as regiões brasileiras. A parte qualitativa, através dos estudos de caso, permitiu conhecer, de forma mais contextualizada e detalhada, algu- 
mas das experiências detectadas na primeira etapa da pesquisa, considerando a percepção dos vários sujeitos nelas envolvidos.

Este artigo analisa, especificamente, as experiências de ampliação de jornada escolar de dois municípios brasileiros: Santarém (PA) e Belo Horizonte (MG), tendo como categoria central a constituição de territórios educativos, na perspectiva da Educação Integral e da cidadania. Procura, com esta análise, mostrar que, apesar de realidades sociais diferentes e formatos de propostas de ampliação de tempo bastante distintos, podemos perceber, nessas experiências, uma concepção de Educação Integral intimamente relacionada ao direito das crianças, jovens e adolescentes de viver uma Educação Integral como um direito de cidadania.

\section{As experiências de ampliação de jornada escolar ${ }^{2}$}

\section{O programa Escola da Gente}

Santarém pertence ao estado do Pará, na região Norte do país. O município, que ocupa uma área de $22.887,08 \mathrm{~km}^{2}$ e tem uma população de 276.665 , possui mais de 400 comunidades rurais distribuídas nas regiões dos rios e várzeas e na zona do planalto.

A Secretaria Municipal de Educação de Santarém (SEMED) se propõe a

desenvolver uma educação de qualidade na rede pública municipal de Santarém, através de um processo democrático, participativo, visando à formação integral do educando para efetivo exercício da cidadania $\mathrm{e}$ construção de uma sociedade comprometida com a promoção humana (PREFEITURA DE SANTARÉM).

A Rede Municipal de Ensino de Santarém conta com aproximadamente 470 escolas e 6.200 alunos. Para atender a essas escolas, a Secretaria se organiza através de Assessorias e Coordenações, divisões e Seções. Duas dessas

2 Esta parte do artigo é uma síntese pessoal do relatório da pesquisa: Educação Integral/ Educação Integrada e (m) Tempo Integral: Concepções e Práticas na Educação Brasileira: Mapeamento das experiências de jornada escolar ampliada no Brasil: Estudo Qualitativo - Município de Santarém, Município de Belo Horizonte. 
assessorias atendem às especificidades regionais do município: Assessoria de Rios e Assessoria do Planalto.

É interessante perceber que o organograma da Secretaria de Educação procura contemplar a diversidade de realidades do município. O Rio e o Planalto são compreendidos como espaços sociais que trazem especificidades próprias, o que faz com que a Secretaria mude sua forma de estruturação, passando da clássica organização por níveis de ensino para uma organização centrada nos territórios.

Em relação à proposta pedagógica, a Secretaria Municipal de Educação implantou o Programa Escola da Gente, que se desdobra em uma série de projetos tendo como referência a participação dos sujeitos, a valorização da cultura local e a preservação do meio ambiente. Ele foi construído com o objetivo de desenvolver a formação integral dos estudantes, articulando a aprendizagem escolar com a formação social, ética, estética e corporal. É o que relata a prof. Lucineide, secretária municipal de Santarém:

[...] garantir o acesso permanente com sucesso da criança na escola; melhoria da qualidade social da educação; ética na gestão dos recursos trabalhar com transparência, fortalecimento do instrumento democrático - conselhos; humanização da escola; constituição da cultura da paz, [...] incentivar a tolerância, o respeito à diversidade, valorizar o outro, valorizar a ética, a estética e a corporeidade, investir no ser e no conviver (LEITE et al., 2010a, p. 15).

Entre os projetos do programa Escola da Gente, há alguns que estão mais voltados para o meio ambiente: Agenda 21 e Escola da Floresta; outros relacionados à arte, cultura e literatura: Arte na escola da gente e Casinha de Leitura; e outros mais, ligados ao esporte: Estrelinhas entre linhas. Além desses projetos, algumas escolas municipais começaram, em agosto de 2009, a fazer parte do programa Mais Educação.

Dentre os projetos, o "Arte na Escola da Gente" se destaca por procurar educar através das linguagens artísticas, entrelaçando família, escola e comunidade. Para atingir seus objetivos, o Arte na Escola da Gente conta com uma equipe de coordenadores e arte-educadores, em geral, artistas com grande experiência, que se identificam com os objetivos do projeto.

O projeto Arte na Escola da Gente desenvolve suas atividades através de oficinas nas escolas da área urbana e de caravanas nas escolas das regiões de Rios e de Planalto. O princípio para participação dos alunos nas oficinas é a 
adesão, mas há situações em que a procura por vagas é maior do que a oferta e nesses casos os alunos com menor rendimento escolar são encaminhados para participarem das atividades.

Apesar da equipe de arte-educadores não fazer parte do quadro de educadores das escolas, há uma tentativa de aproximação com a instituição escolar por parte da coordenação do projeto. O contato dos arte-educadores com a família e com o bairro também é aspecto fundamental no trabalho, como destaca a coordenadora do Projeto:

No final do ano a gente fala com o diretor, mas o nosso contato maior é com a criança mesmo e a comunidade, a casa dela. Tem arte-educador que vai visitar a casa e às vezes conhece o bairro todo [...]; fazem oficina com os pais também, para conquistar os pais, [...] dá oficina de artesanato para os pais de bairro pobre, que se quiserem aprender podem vender e ter uma geração de renda para as mães. Essa experiência deu resultado: já estão produzindo e vendendo (LEITE, et al., 2010a, p. 30).

Se o trabalho nas escolas urbanas se desenvolve através das oficinas, nas regiões de Rios e de Planalto ele acontece através das Caravanas. As Caravanas têm o objetivo de levar o projeto Arte na Escola da Gente às comunidades ribeirinhas e rurais do município. Apesar de acontecer de forma esporádica, ela tem uma abrangência maior, atingindo todos os estudantes e também a comunidade. Um elemento que se destaca, nessa experiência, é a presença e a participação efetiva da comunidade, com os pais e moradores do bairro participando das oficinas. Podendo durar até três dias, essas caravanas transformam comunidades isoladas em espaços de arte e cultura.

O projeto Arte na Escola da Gente também realiza atividades culturais para a cidade de Santarém, entre elas as Mostras Culturais promovidas a cada semestre em espaços abertos, como praças e parques, com o objetivo de divulgar os trabalhos desenvolvidos nas oficinas e o Festival de Interpretação Musical. Além disso, os alunos das oficinas apresentam-se também em outros eventos que ocorrem no município, como na Mostra de Teatro Amador, em que os alunos da oficina de teatro de uma escola municipal apresentaram uma peça infantil. Todas essas atividades fazem o Projeto Arte na Escola da Gente sair dos muros da escola e ocupar o espaço da cidade.

Assim, a preocupação em criar espaços de arte e cultura, em todas as comunidades, mesmo as mais distantes, é aspecto a ser destacado no projeto. É 
interessante ressaltar que, nesse processo, há uma preocupação, por parte dos arte-educadores, com a cultura local, procurando respeitar as especificidades de cada realidade dentro do município, como ressalta este arte-educador:

E nas comunidades por onde tenho passado tenho observado algumas mudanças de cultura de uma comunidade para a outra, às vezes uma comunidade fala pouco, outras falam muito; até dentro da sala de aula o comportamento das crianças é totalmente diferente de uma comunidade para outra, zona urbana, zona rural e a gente dança conforme o ritmo da música (LEITE, et al., 2010a, p. 31).

Além da arte e da cultura, outro eixo norteador da política municipal de educação de Santarém é a educação ambiental, concretizada através da criação, em 2008, da Escola da Floresta, com o objetivo de transformar a floresta em uma enorme sala de aula. Com uma área de 33 hectares de floresta, a Escola da Floresta, localizada na comunidade de Caranazal, próxima a Alter do Chão, é uma parceria da prefeitura de Santarém e do Conselho Nacional dos Seringueiros (CNS), transformando a área em um laboratório vivo de educação ambiental.

A equipe da Escola da Floresta é composta por uma coordenação e por educadores de diversas áreas, contando, inclusive, com educadores populares, como o "Senhor Mucura", seringueiro e membro do Conselho Nacional dos Seringueiros.

Para atender as escolas, a Escola da Floresta conta com um micro-ônibus próprio para buscar os alunos pela manhã e levá-los às escolas de origem no final da tarde. Além das escolas, o projeto realiza eventos e recebe visitas de outros setores da sociedade, como associações, ONGs e outros grupos organizados. Nesse sentido, a Escola da Floresta tem sido um espaço privilegiado de educação ambiental na cidade de Santarém.

A seleção das escolas participantes é feita através de adesão, já que no início do ano é construído um cronograma de atendimento a partir das demandas recebidas. Definidas as escolas, o atendimento é feito por turmas e a visita à Escola da Floresta dura todo o dia. Assim, as escolas atendidas enviam, cada dia, uma turma de cerca de 40 alunos que, dividida em grupos, percorre trilhas sob a responsabilidade dos educadores do Projeto. Durante as trilhas, os grupos têm a oportunidade de conhecer inúmeras espécies florestais, visitar por dentro uma casa de seringueiro, aprender como se faz farinha de mandioca, caminhar por um viveiro com capacidade produtiva de 80 mil mudas, participar de aulas práticas sobre o processo de reprodução de abelhas sem ferrão. 
Depois das trilhas, os grupos se encontram na sede, onde almoçam e conversam sobre a experiência vivida. Nesse espaço, eles discutem sobre meio ambiente, seus problemas e suas formas de preservação e sobre como, no dia a dia, ter atitudes ecológicas. Apesar das atividades serem desenvolvidas pelos educadores do Projeto, cada turma é acompanhada por um ou dois professores, que participam ativamente do debate e têm a função de continuar o trabalho na volta â escola.

Dentro da Escola da Floresta há o Memorial Chico Mendes - com fotos, livros e artigos sobre a história desse seringueiro e líder ambiental, que é visitado por todas as turmas e, de certa forma, é o símbolo da luta e compromisso da Escola da Floresta por uma cidadania planetária.

Construindo uma política educacional com referência na realidade da região, entendendo o rio e o planalto como territórios educativos, envolvendo a comunidade nas atividades da escola e a escola nas atividades da comunidade, a experiência de Santarém aponta para uma concepção de Educação Integral que tem como centro os sujeitos, inseridos em uma realidade sociocultural.

\section{O programa Escola Integrada}

Localizada na região Sudeste, Belo Horizonte é o sexto municipio mais populoso do Brasil, com 2.452.617 habitantes. Sua região metropolitana é composta por 34 municípios, com uma população estimada de 5.397 .438 habitantes, sendo considerada a terceira maior aglomeração urbana do Brasil.

O Sistema Municipal de Ensino de Belo Horizonte, instituído em 1998, é composto por instituições de educação infantil, fundamental e médio, mantidas pelo poder público municipal; instituições de educação infantil criadas e mantidas pela iniciativa privada e órgãos municipais de educação, tais como a Secretaria Municipal de Educação e o Conselho de Municipal de Educação. A Rede Municipal de Ensino é composta por aproximadamente 200 escolas e 150.000 alunos. A Secretaria Municipal de Educação tem como missão "proporcionar a aprendizagem, formação integral, cidadania, produção de conhecimento, pensamento critico e autônomo [...] desenvolvimento, qualidade de vida e dignidade [...] à população belorizontina"3. Atualmente, a prefeitura de Belo Horizonte destina 30,5\% do seu orçamento à Educação, para que esses objetivos sejam alcançados.

Para atingir esses objetivos, a Secretaria desenvolve uma série de projetos como: Escola Integrada, Programa Primeira Escola, BH sem Analfabetos, ProJo-

3 Secretaria Municipal de Belo Horizonte. Disponível em: <http://www.pbh.gov.br/ensino/ smed/> Acesso em: 01/04/2010. 
vem, BH para Crianças, Transporte Escolar Regular, Inclusão de Pessoas com Deficiência, Kit Escolar e Literário, Literatura Afro, Programa Família-Escola, Escola Aberta, Bolsa Escola Municipal, Cadastro Escolar, Projeto de Ação Pedagógica, Programa Rede pela Paz, Sistema de Gestão Escolar, Inclusão Digital, Relações Étnico-Raciais e de Gênero, Avalia BH e Monitoramento da aprendizagem.

A reflexão sobre uma Educação Integral, centralizada nos sujeitos, na Rede Municipal de Educação de Belo Horizonte, ganha força na década de 1990, com a implantação do Programa Escola Plural, que trouxe uma série de desafios para a rede municipal, entre eles garantir a universalização do ensino. Nos mais de 10 anos de experiência, a Escola Plural apontou novas demandas, como a necessidade de ampliação da jornada escolar, concretizada através de um Projeto de Lei proposto por um vereador e aprovado pela Câmara Municipal.

Buscando atender às exigências da lei, primeiramente a Secretaria criou uma escola de tempo integral: a Escola Municipal Monteiro Lobato. Posteriormente, tendo como referência alguns projetos desenvolvidos com jovens da Rede Municipal, como a Rede do $3^{\circ}$ Ciclo e experiências de outros municípios como o Bairro-Escola, de Nova Iguaçu, a SMED implanta o programa Escola Integrada.

Já na sua origem há uma preocupação com o diálogo com a cidade, como relata a coordenadora do Programa Escola Integrada, professora Neusa Macedo:

\begin{abstract}
A gente tinha que pensar no formato [...] que dialogasse mais com a cidade, que incluísse outros atores, esses novos perfis de profissionais então ela surgiu daí. [...] em busca de construir um projeto que tivesse a cara da prefeitura, da secretaria, sobretudo que dialogasse mais com a cidade e, sobretudo, que criasse uma rede de corresponsabilidade, para não ficar uma coisa centrada somente na Secretaria de Educação (LEITE, et al., 2010b, p. 22).
\end{abstract}

Assim, a partir de um debate entre escolas da Rede Municipal, universidades e ONGs, foi construído o Programa Escola Integrada, na perspectiva de se construir uma escola que dialogasse com a cidade, compreendida como cidade educadora, e uma rede de corresponsabilidade social, a partir de uma política intersetorial. Nessa perspectiva, a proposta não se prende a um modelo escolar, buscando transformar os espaços da comunidade em espaços de formação. Também amplia as dimensões da formação dos sujeitos para além 
da dimensão cognitiva, valorizando os aspectos éticos, estéticos, corporais e emocionais, trazendo, para o Programa, outros saberes, construídos a partir da experiência, principalmente com a presença de novos perfis profissionais, como no caso dos agentes culturais.

A entrada das escolas no Programa é feita por adesão, o mesmo acontecendo com os alunos que dele participam. Cada escola apresenta o Programa aos pais, que podem optar, ou não, por inscrever o filho. Apesar da necessidade de adequação à realidade de cada escola, o Programa Escola Integrada tem uma estrutura comum de funcionamento. Tais orientações possibilitam que cada escola estruture e tenha uma autonomia na sua organização, mas dentro de referências comuns a todas as experiências.

O Programa garante nove horas diárias de atendimento educativo para os estudantes, por meio de atividades de acompanhamento pedagógico, cultura, esportes, lazer e formação cidadã. Para isso, são oferecidas oficinas de: Acompanhamento pedagógico/Conhecimentos específicos, Meio Ambiente, Esporte e Lazer, Direitos Humanos e Cidadania, Cultura e Artes, Inclusão Digital e Saúde, Alimentação e Prevenção.

Cada escola, ao aderir ao Programa, constitui um grupo de educadores, com um professor da Rede Municipal como coordenador, além de agentes culturais e monitores-estudantes das universidades parceiras, que ministram as oficinas.

O Programa Escola Integrada tem como proposta a construção de uma política de gestão territorial da educação, como afirma a prof. ${ }^{a}$ Macaé, secretária municipal de Educação:

o primeiro grande desafio que o programa da Escola Integrada coloca para a instituição escolar é de pensar em uma gestão territorial da educação, pensar a escola dentro de determinado território, compondo uma rede de educação integral com várias outras instâncias também educativas que você tem na comunidade.Assim, há, nas orientações do Programa, a proposta de uso dos espaços da cidade, especialmente aqueles do bairro em que a escola se localiza, como colocado pela Secretaria no documento: Orientações Gerais para as escolas, de fevereiro de 2009 (LEITE, et al., 2010b, p. 40).

$\mathrm{O}$ atendimento aos alunos no Programa Escola Integrada deve acontecer prioritariamente nos espaços parceiros externos à escola. Internamente serão garantidas adequações das UANs (Unidades de Alimentação e Nutrição), instalações sanitárias e vestiários, uma vez que estes atendimentos, alimentação e 
higiene, devem acontecer dentro da escola. Será cuidada também a questão da acessibilidade geral das edificações. Outras intervenções físicas serão possíveis em função de particularidades de cada escola/comunidade.

Buscando apoiar a utilização desses espaços, a Secretaria cria formas de garantir a manutenção deles:

O uso de espaços na comunidade para o desenvolvimento das oficinas (creches, associações, igrejas, etc.) devem ser firmados mediante contratos de comodato com a instituição cedente do espaço, de preferência sem ônus financeiro para a Caixa Escolar. $\mathrm{Na}$ impossibilidade, a Caixa Escolar poderá destinar verba para a manutenção e conservação do espaço cedido (LEITE, et al., 2010b, p. 27).

A perspectiva é a da constituição de territórios educativos, visando à sua ressignificação, como explica a professora Neusa:

É concepção, do bairro-escola mesmo, a gente trabalha com isso. A gente quer que se dê nesse território, constituindo um território educativo os alunos trabalham muito nesse sentido de demarcar esse território, esse percurso educativo, por onde circula para a aprendizagem. Muitos desses espaços já estão modificados, alterados por esse uso: pintam as paredes... é um objetivo do programa, esse diálogo com a comunidade tanto na cessão e uso dos espaços, é aquele território que educa, até para ela estar reconhecendo que sozinha não pode mais, que é preciso que se forme essa rede e ampliar esse território, para poder dar conta de atender esses meninos, tanto no espaço físico quanto no potencial educativo. A gente tem relatos de pessoas que cedem, não só cedem, mas também contribuem com a escola - vamos até fazer um prêmio simbólico para parcerias (LEITE, et al., 2010b, p. 38).

A relação com a comunidade, na Escola Integrada, é um processo construí-

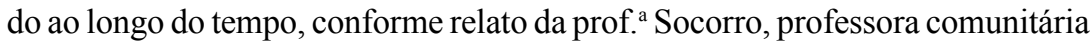
da Escola Municipal Paulo Freire: 
A comunidade resistiu muito, que quebra Igreja, portão que faz barulho na rua, então foi um desafio também à comunidade. $\mathrm{O}$ que me chamou mais a atenção é que a mesma comunidade que resistiu começou a mudar o olhar mesmo. Primeiro foi um piquenique: a gente levava violão, flauta, para naquela porta e toca alguma coisa; do lanche chama o pessoal e oferece. A comunidade reuniu e já tem canteiro de horta, canteiro de jardim: ali onde tem parada, apita e para, sabe que tem que parar; o pessoal mais velho se reuniu, recolheu o lixo e fez alguns banquinhos, para os meninos sentarem. A questão da integrada [...] mudou a cara da escola, da comunidade, do pessoal da igreja também (LEITE, et al., 2010b, p. 33).

Em muitas escolas, os pais também participam dos eventos ocorridos dentro e fora da escola. No começo do Programa, muitos eram resistentes e achavam que não iria dar certo. Porém, com o passar dos anos, foram percebendo a importância de "ultrapassar os muros da escola". É o que revelam estes depoimentos pais:

Eles saíam da escola e continuavam aprendendo, sem aquela tortura de ficar sentado, sem ficar escrevendo, era brincando... aprendia sem ser aquela brincadeira exagerada, correndo solto por aí, sem ninguém para olhar (LEITE, et al., 2010b, p. 33).

O que gosto muito na escola integral é a convivência de pessoas, dos adolescentes, de se envolver com os meninos pequenos, acho muito legal. É difícil pôr todo mundo numa mesma escola - acho bem todos lá na quadra, os pequenos e os grandes, acho o maior barato, uma mistura de raça, de cor, de cabelo ruim e cabelo bom (LEITE, et al., 2010b, p. 35).

Buscando uma interação com a cidade, o Programa fez uma parceria com o museu a céu aberto Inhotim ${ }^{4}$. A proposta não se resume a uma visita, como explica a professora Macaé:

4 O instituto Inhotim, localizado em Brumadinho, região metropolitana de Belo Horizonte, caracteriza-se por oferecer um grande conjunto de obras de arte, expostas a céu aberto ou em galerias temporárias e permanentes, situadas em um Jardim Botânico, de rara beleza. O paisagismo teve a influência inicial de Roberto Burle Marx (1909-1994) e em toda a área são encontradas espécies vegetais raras, dispostas de forma estética, em terreno que conta com cinco lagos e reserva de mata preservada. Disponível em: <http://www.inhotim.org.br/>. Acesso em: 25/06/2010. 
No Inhotim, nós temos três módulos: no primeiro, eles vão - crianças, professores e agentes culturais, as crianças passam por formação e os professores também têm uma agenda de formação; as escolas que desenvolvem projetos na área podem fazer um $2^{\circ}$ Módulo de ida a Inhotim para apresentação de seus projetos, para desencadear outros cenários, para aprofundamento, e então a gente também está tentando construir com o Inhotim a idéia de um percurso educativo que não fique só na primeira visita ou que se possa construir perspectivas diferentes de ida e volta para avançar em diferentes aspectos da formação das crianças (LEITE, et al., 2010b, p. 36).

A concepção de cidade educadora acaba gerando a necessidade de uma rede de atendimento na cidade, a partir de uma política intersetorial, como ressalta a professora Macaé:

Ele [o programa Escola Integrada] força, de certa forma, o próprio município para além da Secretaria de Educação a desenvolver no território uma série de intervenções, que é esse conceito de cidade-educadora: que fazer educação de qualidade não é só uma política de educação escolar, a gente precisa trabalhar com outros setores - por exemplo, quando as crianças começam a transitar no bairro, um lixão que está do lado da escola passa a incomodar. $\mathrm{O}$ engraçado é que ele sempre esteve do lado da escola, mas até a escola integrada ele não incomodava - as crianças sempre passavam por ele indo e vindo da escola; mas é que ele deixa visível uma série de questões no território em que as crianças estão inseridas e todas as instituições se sentem responsáveis, torna-se um marco que está lá no Estatuto da Criança e do Adolescente que é de pensar a educação e a proteção integral da criança e do adolescente. Que a escola é fundamental nessa rede, mas que tem outros atores que precisam atuar (LEITE, et al., 2010b, p. 37).

O programa Escola Integrada procura, assim, criar uma gestão territorial da educação, envolvendo a escola e várias instituições e organizações da sociedade civil, possibilitando um trabalho mais integrado. Também os programas do Ministério da Educação, como o programa Mais Educação e de outros Ministérios como o programa Segundo Tempo, do Ministério dos Esportes, passam a fazer parte dessa Rede.

Assim, mesmo enfrentando problemas e contradições, apontados na pesquisa e não trabalhados neste texto, o programa "Escola da Gente" de Santarém 
e "Escola Integrada" de Belo Horizonte propõem e experimentam uma Educação Integral que sai dos muros da escola e ocupa a cidade, entendendo esse processo como um direito das crianças, jovens e adolescentes.

\section{Territórios educativos: encontro entre experiência social e conhecimento}

Primeiramente, é importante destacar que, como nos coloca Paulo Freire (1970), “a educação não é neutra", e que as escolhas feitas por esses dois municípios são opções não só pedagógicas, mas fundamentalmente políticas, revelando uma determinado projeto de sujeito, de sociedade e de educação. A ampliação do tempo, por si só, não garante um projeto educativo; é preciso analisar como esse tempo está sendo utilizado, que práticas estão sendo desenvolvidas, que relações educativas estão sendo estabelecidas.

Contrariando o senso comum que, muitas vezes, enxerga a escola em tempo integral como uma forma de "tirar as crianças e os jovens da rua" - vista como espaço de perigo e de violência, as duas experiências abrem as portas da escola e ocupam a cidade. O tempo é empregado para que crianças, jovens e adolescentes possam viver a experiência de ser cidadão, de participar da vida da cidade em suas várias manifestações, de usufruir de seus bens culturais, de se sentirem sujeitos de suas cidades. Nesse sentido, as duas cidades se transformam em cidades educadoras que, como destaca Moll (2005, p. 15), implica em:

- re-conceitualizar a cidade, entendendo-a, no seu emaranhado de ruas, avenidas, praças e prédios, como um território de múltiplas histórias e culturas e, por isso, de incontáveis possibilidades educativas;

- implica discutirmos quem somos, que necessidades comuns e singulares temos, que presente e que futuro desejamos;

- implica assumirmos, governos, associações de moradores, empresariado, movimentos sociais, grupos de jovens, igrejas, sindicatos, universidades, como diferentes atores sociais do cenário urbano - tarefas educativas no sentido de mapear demandas e possibilidades formativas, para oferecer ao e construir com o conjunto da população inéditos viáveis que permitam fazer da vida algo mais ou algo distinto do que ela é. 
Esta re-conceitualização pressupõe a compreensão da cidade como uma grande rede ou uma grande malha de espaços pedagógicos formais (escolas, creches, faculdades, universidades, institutos) e informais (teatros, praças, museus, bibliotecas, meios de comunicação, repartições públicas, igrejas, além do trânsito, do ônibus, da rua) que pela intencionalidade das ações desenvolvidas, pode converter a cidade em território educativo, pode fazer da cidade uma pedagogia (MOLL, 2005, p. 15).

Mas e o processo de conhecimento? Como a vivência da cidade pode se traduzir em processo de aprendizagem? São questões que as experiências também têm muito a nos ensinar, já que, ao fazer da cidade uma pedagogia, as experiências de Belo Horizonte e de Santarém procuram superar uma experiência bastante presente na história da educação escolar: a relação entre experiência social e conhecimento. Como nos coloca Arroyo (2011, p. 116):

O currículo é tratado como se fosse possível a separação entre experiência e conhecimento. A produção do conhecimento é pensada como um processo de distanciamento da experiência, do real vivido, o real pensado seria construído por mentes privilegiadas através de métodos sofisticados, distantes do viver cotidiano, comum. Logo, o conhecer visto como um processo distante do homem e da mulher comuns, do povo comum; distante até do docente que ensina o povo comum. Todos eles - povo, mestres - são vistos como incapazes da produção do conhecimento porque estão atolados na sobrevivência, no real vivido. Consequentemente, serão apenas capazes de produzir o saber da experiência comum, do senso comum (ARROYO, 2011, p. 116).

Essa dicotomia acaba por reforçar a desigualdade e a exclusão em nosso país, que aparecem também na forma de racismo e discriminação cultural, e não só como exploração econômica. Como nos coloca Dagnino (2000, p. 82):

ser pobre significa não apenas privação econômica e material, mas também ser submetido a regras culturais que implicam uma completa falta de reconhecimento das pessoas pobres como sujeito, como portadores de direitos [...]. Essa privação cultural imposta pela ausência absoluta de direitos, que em última instância se expressa como uma supressão da 
dignidade humana, torna-se então constitutiva da privação material e da exclusão política (DAGNINO, 2000, p. 82).

Incluídos não só dos bens materiais de nossa sociedade, mas privados de suas manifestações culturais e de suas formas de expressão, crianças e jovens das camadas populares vivem uma cisão - não conseguindo identificar o educativo em sua experiência cultural, nem encontrar, na escola, um espaço para compreender sua realidade social. A consequência desse processo, como nos coloca Arroyo (2011, p. 141), acaba sendo a reprodução da desigualdade:

Na raiz mais profunda dessa ausência e segregação de determinados sujeitos do campo do conhecimento está a perversa relação política de inferiorização racial que acompanha nossa história, que o campo do conhecimento e da cultura, da escola reproduz: as tentativas de manter os coletivos étino-raciais como invisíveis, à margem (ARROYO, 2011, p. 141).

As experiências de Santarém e Belo Horizonte ousam seguir um caminho distinto, constroem novas trilhas educativas, rompem barreiras, ampliam espaços, criam territórios, entendidos não só como espaço geográfico, mas como relações socais (SANTOS, 2000) Dessa forma, possibilitam processos de aprendizagem não só para os alunos, mas também para os professores. Como ressalta Torres Santomé (2001, p. 233)

cuando un profesor o profesora apuesta por defender la democracia, tratando de ejercer como ciudadana o ciudadano, preocupándose por su barrio, por colectivos sociales desfavorecidos, por los derechos de las mujeres, de las personas minusválidas, de inmigrantes, etc., llega un momento en que cae en la cuenta de que también los centros de enseñanza son lugares importantes en su lucha (TORRES SANTOMÉ, 2001, p. 233).

Talvez a grande contribuição dessas duas experiências para o debate da Educação Integral no Brasil se traduza na possibilidade concreta que elas apresentam de acabar com a separação entre escola e vida, construindo uma ponte entre a experiência social e a aprendizagem escolar, ponte esta assentada 
sempre sobre um espaço, que, ao ser apropriado pelos sujeitos - estudantes, profissionais da educação, pais, moradores da cidade -, passa a se constituir em território educativo.

\section{REFERÊNCIAS}

ARROYO. M. Currículo, território em disputa. Petrópolis: Vozes, 2011.

DAGNINO, E. Cultura, cidadania e democracia: A transformação dos discursos e práticas na esquerda latino-americana. In: ALVAREZ, S. E.; DAGNINO, E.; ESCOBAR, A. Cultura e política nos movimentos sociais latino-americanos: novas leituras. Belo Horizonte: Ed. UFMG, 2000. p. 61-102.

FREIRE, P. Pedagogia do Oprimido. Rio de Janeiro: Paz e Terra, 1970.

LEITE, L. H. A. et al. Educação Integral/Educação Integrada e(m) Tempo Integral: Concepções e Práticas na Educação Brasileira: Mapeamento das experiências de jornada escolar ampliada no Brasil: Estudo Qualitativo - Santarém (PA). Belo Horizonte: Universidade Federal de Minas Gerais, 2010a. Relatório técnico.

LEITE, L. H. A. et al. Educação Integral/Educação Integrada e(m) Tempo Integral: Concepções e Práticas na Educação Brasileira: Mapeamento das experiências de jornada escolar ampliada no Brasil: Estudo Qualitativo - Belo Horizonte (MG). Belo Horizonte: Universidade Federal de Minas Gerais, 2010b. Relatório técnico.

MOLL, J. Juventude, cidade e espaços de convivência e aprendizagem: novos olhares. Disponível em: $<$ http://portal.aprendiz.uol.com.br $>$. Acesso em: 30/1/2012.

PREFEITURA DE SANTARÉM. Disponível em: <www.santarem.pa.gov.br $>$ Acesso em: $1 / 4 / 2010$.

SANTOS, M. O espaço do cidadão. São Paulo: Nobel, 2000.

TORRES SANTOMÉ, J. Educación en tiempos de neoliberalismo. Madrid: Morata, 2001.

Texto recebido em 25 de março de 2012.

Texto aprovado em 19 de abril de 2012. 